\title{
A PRODUÇÃO PARA AUTOCONSUMO NA AGRICULTURA FAMILIAR: UMA QUESTÃO DE LIBERDADE ALIMENTAR
}

Josiane Gracieli Preschlak Fiorese ${ }^{1}$

Clério Plein ${ }^{2}$

\begin{abstract}
RESUMO: A produção de autoconsumo é uma prática clássica de reprodução social da agricultura familiar, sendo que este tipo de produção desempenha funções importantes no meio rural contemporâneo, apesar das profundas transformações ocorridas com o passar dos anos. A questão central do presente trabalho é analisar a percepção de agricultores familiares em relação à produção de alimentos para o autoconsumo, trata-se de uma revisão bibliográfica sobre o tema. No Brasil a produção de autoconsumo está presente na maioria dos estabelecimentos agropecuários, sendo mais prevalente em propriedades familiares. A produção de alimentos para autoconsumo é prevalente na agricultura familiar, sendo que a intensidade, a forma e os motivos pela qual é praticada é peculiar de cada local e grupo de indivíduos, contudo é possível identificar que ambos os segmentos possuem ideias compartilhadas. Portanto, entende-se que a produção para autoconsumo na agricultura familiar possui diversos significados (biológico; ambiental; político; social; cultural; econômico e ético), ou seja, trata-se de uma questão de liberdade alimentar.
\end{abstract}

Palavras-chave: Autoconsumo. Agricultura Familiar. Liberdade Alimentar.

\section{PRODUCTION FOR SELF-CONSUMPTION IN FAMILY AGRICULTURE: A QUESTION OF FOOD FREEDOM}

\begin{abstract}
The production of self-consumption is a classic practice of social reproduction of family agriculture, and this type of production plays important roles in the contemporary rural environment, despite the profound changes that have occurred over the years. The central issue of the present work is to analyze the perception of family farmers in relation to the production of food for self-consumption, it is a bibliographical review on the subject. In Brazil the production of self-consumption is present in most agricultural establishments, being more prevalent in family farms. The production of food for self consumption is prevalent in family agriculture, and the intensity, form and reasons for it is peculiar to each place and group of individuals, but it is possible to identify that both segments have shared ideas. Therefore, it is understood that the production for self-consumption in family agriculture has several meanings (biological, environmental, political, social, cultural, economic and ethical), that is, it is a matter of food freedom.
\end{abstract}

Keywords: Self-consumption. Family farming. Freedom Food

\section{Introdução}

A produção de autoconsumo é uma prática clássica de reprodução social da agricultura familiar, porém seguidamente é invisível em estudos rurais e políticas públicas. São várias as denominações utilizadas para autoconsumo ${ }^{3}$, como a produção para "autoprovisionamento" ou "pro gasto" (GRISA et al., 2010). Também descrito como produção de subsistência, mínimo calórico e como consumo propriamente dito (GAZOLLA; SCHNEIDER, 2007). Muitas vezes, classificada como "marginal" ou "insignificante" economicamente, este tipo de produção é tradição recontextualizada, sendo uma estratégia recorrente no mundo rural contemporâneo (GRISA et al., 2010).

\footnotetext{
${ }^{1}$ Mestre em Agroecologia e Desenvolvimento Rural Sustentável - UFFS.

${ }^{2}$ Doutor em Desenvolvimento Rural - UFRGS.

${ }^{3}$ De acordo com Grisa et al (2010, p. 66), "o autoconsumo refere-se a toda produção realizada pela família cujos produtos são destinados ao se próprio consumo. Diz respeito ao cultivo de alimentos para o consumo familiar (horta, pomar, criação de animais, etc.) e dos animais presentes no estabelecimento, à fabricação de ferramentas e à produção de insumos para o processo produtivo".
} 
A partir dos anos de 1970, com o processo de modernização da agricultura brasileira, denominado de Revolução Verde, a produção para autoconsumo também sofre mudanças importantes (GAZOLLA; SCHNEIDER; 2007). Nesse período, devido às intensas transformações técnicas e produtivas, os agricultores familiares adotaram a lógica de mercado, apresentando como consequência a perda da autonomia no processo produtivo, bem como da tradição e do saber sobre a produção destinada ao consumo próprio (SCHNEIDER, 2009).

A produção agrícola que antes apresentava características de policultivos, diversificação e garantia das necessidades básicas familiares, passa a ser representada por sistemas produtivos especializados, com produção restrita de produtos e direcionada ao mercado, em detrimento da produção destinada ao consumo familiar (GAZOLLA; SCHNEIDER, 2007). Os autores Machado; Machado Filho (2014) demonstraram em seu estudo, que inúmeras espécies desapareceram com a expansão da "Revolução Verde". Nesse sentido, a perda anual de espécies em virtude da ação humana é de 50 a 100 vezes superior aos índices de extinção decorrentes de motivos naturais. Nota-se também, sua relação com a miséria no campo, expulsão de pequenos agricultores, aumento da marginalidade e da criminalidade, destruição da biodiversidade, agressão e contaminação ambiental, bem como da concentração de terra e capital.

Ao refletirmos sobre o acesso de alimentos de qualidade é inevitável destacarmos como a agricultura se desenvolve em nosso país. Uma das formas é a agricultura hegemônica, com grandes áreas de terra, produzindo essencialmente commodities e altamente dependente de insumos químicos. A outra é a não hegemônica, a qual a agricultura familiar faz parte, que atua na contra hegemonia com o desenvolvimento de alternativas produtivas (FONINI; LIMA, 2013).

Diante do processo de vulnerabilização citado, a produção de autoconsumo apresenta-se como importante atividade em várias esferas da agricultura familiar, que atuam nesta contra hegemonia (GAZOLLA; SCHNEIDER, 2007). Enquanto estratégia de reprodução social, a importância da produção de autoconsumo, é mais expressiva em situações onde há um agravamento dos recursos monetários. Dessa forma, quando se dispõe de alimentos produzidos pela família para a alimentação, a renda obtida através da venda de pequenos excedentes, com o trabalho assalariado ou de benefícios de programas públicos, pode suprir outras necessidades, como saúde, educação, vestuário e habitação (GADELHA; MALUF; 2008).

Segundo Garcia Júnior (1989), a produção de autoconsumo representa também uma característica de alternatividade, isto é, possibilita tanto o consumo como a transformação destes em valores de troca. Neste processo, algumas características são relevantes como a necessidade familiar, condições de preços, perecibilidade, entre outros. Para Maluf et al., (2001, p. 16), a produção de autoconsumo representa um "importante instrumento de proteção frente às incertezas e oscilações da produção mercantil”. A inexistência de condições adequadas para este 
tipo de produção é responsável pela insuficiência alimentar, bem como por indicadores de pobreza rural medidos através da renda monetária.

O autor Antonio Candido (2001), diante da complexidade dos fenômenos envolvidos para a sobrevivência dos indivíduos, propôs a "sociologia dos meios de subsistência", visto que as necessidades apresentam um duplo sentido, o natural e o social. Esse modo de produção não está apenas relacionado com a existência física, mas é determinada pela maneira de viver dos indivíduos. Dessa forma,

Os meios de subsistência de um grupo não podem ser compreendidos separadamente do conjunto das "reações culturais", desenvolvidas sob o estímulo das "necessidades básicas". Em nenhuma outra parte, vemos isto melhor que na alimentação, que é um recurso vital por excelência (CANDIDO, 2001, p. 35).

Nesse sentido, Anjos et al. (2009) ressaltaram que os agricultores familiares não são apenas produtores, mas sim, sujeitos históricos reprodutores de valores de uma cultura. Sendo assim, as práticas de autoconsumo expressam a matriz cultural das famílias rurais.

Os autores Menasche et al. (2008) também contribuíram nesse sentido, ressaltando que os alimentos são indispensáveis para à sobrevivência dos seres humanos e para satisfação de suas necessidades, porém seus indicadores nutricionais são insuficientes quando se deseja compreender os seus significados, visto que os alimentos não são apenas consumidos, mas também, são pensados. Sendo assim, o ato de se alimentar representa uma valoração simbólica. Desse modo,

A comida pode, então, ser tomada como linguagem, como texto cultural que fala do corpo, da família, do trabalho, de relações sociais, de visões de mundo. [...] Nutrindo laços, a comida fala da família e da comunidade. Temperando tradições, a comida atualiza identidades, ao mesmo tempo em que sua hibridização evidencia a proximidade, material e simbólica, entre campo e cidade (MENASCHE et al. 2008, p. 147).

Em muitas regiões rurais a produção para autoconsumo vem se fortalecendo, apesar de inúmeras previsões que esta desapareceria ou definhasse com o passar do tempo. Porém, as razões e significados desse fortalecimento ainda permanecem desconhecidos ou mal interpretados (GRISA, et al. 2010).

Nessa perspectiva, a questão central do presente trabalho é analisar a percepção de agricultores familiares em relação à produção de alimentos para o autoconsumo, visto que esta representa uma estratégia potencial para o desenvolvimento rural. Diante disso, e com a motivação de compreender os motivos de produzir para o autoconsumo e o que esta produção representa para diferentes grupos de agricultores familiares, a pergunta de pesquisa do presente 
estudo é: quais os significados de produzir alimentos para o autoconsumo na agricultura familiar?

No Brasil, a produção para autoconsumo é desenvolvida em $72,72 \%$ dos 5.175 .636 estabelecimentos agropecuários, sendo que em aproximadamente $18 \%$ dos estabelecimentos rurais essa produção representa mais de $90 \%$ do montante total, ou seja, é uma atividade expressiva no setor agrícola. A prática de produzir para autoconsumo é realizada em unidades familiares e não familiares, sendo mais prevalente em propriedades familiares $(85,74 \%)$ do que nas não familiares $(14,26 \%)$ (BRASIL, 2013).

A produção para autoconsumo desempenha vários papéis e funções no meio rural contemporâneo. Diante disso, este tipo de produção é reconhecida como um elemento de promoção da segurança alimentar e nutricional, de redução da pobreza e de inclusão socioprodutiva no meio rural (BRASIL, 2013). Os autores Gazolla e Schneider (2007), destacaram a importância da produção de autoconsumo para a agricultura em virtude do processo de transmissão dos conhecimentos de geração para geração, como instrumento de socialização das famílias e comunidades rurais, como responsável por uma maior autonomia destas, frente ao contexto social e econômico que envolve as unidades de produção e como uma característica essencial, uma vez que está intimamente ligada à continuidade da reprodução social e alimentar dos membros do grupo doméstico.

Nesse contexto, Grisa (2007a) ressaltou que fortalecer a produção de autoconsumo é relevante não apenas por suprir as necessidades alimentares das famílias, mas pelo que ela representa na garantia da segurança alimentar e nutricional ${ }^{4}$, de incremento na condição socioeconômica, de vínculo cultural, para a identidade social e a sociabilidade. Desta forma, a produção de autoconsumo não alimenta apenas o corpo, mas também nutre o (ser) agricultor, o (ser) vizinho, o (ser) parente, a condição social e a sua autonomia.

No estudo Leite (2003) ressaltou-se que o autoconsumo familiar representa um papel decisivo como estratégia para reprodução da unidade familiar, sobretudo no balanço orçamentário, como elemento anticíclico em períodos de baixa nos rendimentos oriundos da comercialização dos produtos.

Estudar as práticas alimentares de famílias rurais, bem como as representações sociais associadas a elas, representa uma forma relevante de compreensão de suas percepções acerca de

\footnotetext{
4 A definição de Segurança Alimentar e Nutricional é estabelecida na Lei no 11.346 , de 15 de setembro de 2006, como "a realização do direito de todos ao acesso regular e permanente a alimentos de qualidade, em quantidade suficiente, sem comprometer o acesso a outras necessidades essenciais, tendo como base práticas alimentares promotoras de saúde que respeitem a diversidade cultural e que sejam ambiental, cultural, econômica e socialmente sustentáveis"(BRASIL, 2006).
} 
temáticas cotidianas destes indivíduos, como a agricultura, a natureza e o rural e o modo como suas vidas tem sido afetada por mudanças recentes ocorridas (MENASCHE, 2007).

O autor Amartya Sen apresenta em sua obra "Desenvolvimento como liberdade" a ideia que o desenvolvimento é essencialmente um processo de expansão das liberdades reais que as pessoas usufruem, assim considera as liberdades individuais como elementos constitutivos básicos para o desenvolvimento do coletivo. É relevante analisar a produção de alimentos para o autoconsumo com foco nesta ideia, pois possibilita uma reflexão em relação a liberdade de consumir uma alimentação que os indivíduos valorizam e as influências disso para a liberdade substantiva dos mesmos.

Em síntese, o referido estudo busca refletir sobre a produção de alimentos para autoconsumo, sob a perspectiva de desenvolvimento apresentada pelo autor Amartya Sen, sugerindo uma terminologia que represente o significado desta produção para os sujeitos da pesquisa.

\section{Autoconsumo e agricultura familiar}

A partir da década de 1970 a agricultura brasileira passou por intensas transformações. A então chamada "pequena agricultura" ou agricultura camponesa presenciou mudanças de elementos característicos com a substituição de práticas e meios de produção. Entre os elementos, pode-se citar a enxada, a tração animal, a carroça, a colheita manual, entre outros que passaram a ser utilizados com menor frequência. Nesse contexto, acreditava-se que também seriam alteradas outras características da agricultura e do meio rural, como a produção para o autoconsumo. Este fato era fundamentado com a consolidação do processo de modernização da agricultura e a consequente perda da importância da produção para autoconsumo (GRISA, 2007b)

No presente estudo, entende-se como produção de autoconsumo a definição utilizada na pesquisa BRASIL (2013), que buscou dimensionar esta expressão e as características desta produção conforme:

O autoconsumo compreende toda a produção realizada pela família e destinada ao seu próprio consumo, incluindo os produtos de origem animal, os produtos oriundos das lavouras permanentes e temporárias, da silvicultura, da floricultura, da extração vegetal e da agroindústria doméstica. Trata-se, nestes termos, de uma produção que é destinada ao ciclo interno da unidade de produção, que acaba se autoaprovisionando com produtos para a própria alimentação e outros usos do estabelecimento (BRASIL, 2013, p. 10). 
Nesse contexto, também é relevante conceituar o termo agricultura familiar, que possui várias definições. Utiliza-se como referência para o estudo aqui apresentado, as considerações realizadas por Abramovay (1997), visto a relevância que estas representam:

A agricultura familiar é aquela em que a gestão, a propriedade e a maior parte do trabalho vêm de indivíduos que mantêm entre si laços de sangue ou de casamento. Que esta definição não seja unânime e muitas vezes tampouco operacional é perfeitamente compreensível, já que os diferentes setores sociais e suas representações constroem categorias científicas que servirão a certas finalidades práticas: a definição de agricultura familiar para fins de atribuição de crédito pode não ser exatamente a mesma daquela estabelecida com finalidades de quantificação estatística num estudo acadêmico. O importante é que estes três atributos básicos (gestão, propriedade e trabalho familiares) estão presentes em todas elas (ABRAMOVAY, 1998, p. 10).

No Segundo Sarandón, p. 78 (2004), um dos maiores desafios a serem enfrentados pela humanidade será a manutenção da produção agrícola aliada a um sistema que conserve os recursos naturais. Para tanto é indispensável que a agricultura seja viável sob aspecto econômico e social, que apresente produção suficiente, que mantenha os recursos naturais e o meio ambiente, seja em nível local, regional e global. Sendo assim, "a agricultura sustentável deve satisfazer as necessidades do presente, sem comprometer as gerações futuras". Esta nova agricultura, requer o conhecimento sobre os componentes do agroecossistema, bem como das interações entre eles.

A produção de alimentos para o autoconsumo está inserida em contexto ambiental, social, cultural, político, econômico e ético, assim pode-se relacioná-la também a agroecologia. Segundo Sarandón; Flores (2014), não se trata de substituir um pacote químico por técnicas verdes, mas sim de potencializar as funções ecológicas dos agroecossistemas. A agroecologia "vai além de aspectos técnicos da produção, valorizando a relação da agricultura com o meio ambiente e as consequências sociais (trata da equidade entre gerações e da produção de alimentos saudáveis para consequente garantia de segurança e soberania alimentar e nutricional), econômico (trata da não dependência dos agricultores a mercado, insumos externos e baixa diversificação), político (processos participativos e democráticos da população rural em relação ao desenvolvimento), ético (diz respeito ao vínculo moral, que inclui o respeito e preservação do meio ambiente, não só para eles, mas também para as gerações futuras) e cultural (considerando os conhecimentos e valores locais da população rural)".

Segundo Grisa, p. 131 (2007a), a existência do autoconsumo nos estabelecimentos rurais justifica-se por fatos como "consumir alimentos sem veneno" e "saber o que está consumindo". Com o objetivo de garantir a qualidade e sanidade dos alimentos, a produção para o autoconsumo geralmente não utiliza agrotóxicos e produtos químicos, estando baseada no uso de 
esterco animal, cinzas, restos de alimentos e materiais que não comprometem a saúde do consumidor, que será a própria família. Sendo assim, esse tipo de produção adota manejos mais sustentáveis, através da utilização e reciclagem dos recursos naturais disponíveis, sem agressão ao meio ambiente.

A autora Menasche (2007) descreveu em seu estudo que é notável a preocupação referente à qualidade dos produtos consumidos pelas famílias rurais e a associação realizada entre o processo produtivo e as características dos alimentos. A produção de alimentos para o autoconsumo passou por mudanças consideráveis, inclusive com quantidades inferiores do que realizada antigamente, infelizmente muitas variedades e espécies crioulas foram perdidas, mas é possível afirmar que os hábitos e tradições de consumo são responsáveis pela manutenção de algumas características no meio rural, como a diversidade de cultivos e a criação de animais.

$\mathrm{Na}$ agricultura de base familiar, o que se produz está diretamente relacionado com o que se come, e desta relação resulta a cultura alimentar local, como observado na pesquisa de Fonini e Lima (2013). Dessa forma, a agricultura faz parte da cozinha e a cozinha da agricultura, o rural e o agricultor são mediadores da relação sociedade-natureza através da produção de alimentos.

Nota-se que a produção de alimentos para o autoconsumo familiar está relacionada com fatores essenciais à própria vida. Para Candido (2001), o alimento pode ser considerado elemento teórico explicativo da vida social. Nesse contexto, pode- se observar transformações importantes no decorrer do processo civilizatório, com modificações e ampliações das fontes de abastecimento alimentar.

Segundo Candido (2001), é fundamental o papel que a alimentação assume nas relações e na caracterização da personalidade dos grupos sociais. Este fato pode ser notado nos diferentes grupos sociais, principalmente em populações chamadas arcaicas, em povos e grupos de progresso técnico limitado e em classes inferiores da população. Nesse sentido, o autor destacou:

Há com efeito para cada cultura uma técnica de viver de que a alimentação faz parte, e a que deve submeter-se a fome para ser satisfeita, não obstante o seu caráter inelutável. Além disso, ela se torna o centro de um dos mais vastos complexos culturais, abrangendo atos, normas, símbolos, representações. A obtenção da comida percorre, do esforço físico ao rito, uma gama vastíssima em que alguns têm querido buscar a gênese de quase todas as instituições sociais (CANDIDO, 2001, p. 36).

Diante da complexidade que a alimentação assume para os diferentes povos é pertinente relacioná-la com o desenvolvimento, visto que vivemos em um mundo desigual e a alimentação é elemento essencial à vida. Nesta perspectiva, o autor Amartya Sen (2010) analisou o desenvolvimento enfatizando as liberdades dos indivíduos como elemento constitutivo, considerando a capacidade das pessoas levarem o tipo de vida que elas valorizam. O papel 
constitutivo está relacionado com a relevância que a liberdade substantiva desempenha no enriquecimento da vida humana. Dessa forma,

Ter mais liberdade para fazer as coisas que são justamente valorizadas é importante por si mesmo para a liberdade global da pessoa e importante porque favorece a oportunidade de a pessoa ter resultados valiosos. Ambas as coisas são relevantes para a avaliação da liberdade dos membros da sociedade e, portanto, cruciais para a avaliação do desenvolvimento da sociedade [...] Ter mais liberdade melhora o potencial das pessoas para cuidar de si mesmas e para influenciar o mundo, questões centrais para o sucesso do desenvolvimento (SEN, 2010, p. 33).

Segundo Sen (2010), o desenvolvimento deve ir além dos interesses relacionados à renda, como a acumulação de capital e o crescimento do Produto Nacional Bruto. A essência do desenvolvimento deve estar relacionada com a melhora da vida dos indivíduos e das liberdades substantivas $^{5}$. O autor também cita em sua obra que o desenvolvimento econômico, da forma como ocorre, pode ser responsável pela eliminação de tradições e herança cultural de um país.

O processo de expansão das liberdades substantivas possibilita que as pessoas exerçam sua função de agente, ou seja, alguém que age e gera mudanças e cujas realizações podem ser julgadas de acordo com seus próprios valores e objetivos. Desta forma, o êxito de uma sociedade deveria ser avaliado, conforme as liberdades substantivas que os membros dessa sociedade desfrutam (SEN, 2010).

Diante do exposto, é relevante a relação que o presente estudo realiza da produção para autoconsumo como estratégia de liberdade substantiva, visto que representa a capacidade dos indivíduos reproduzirem a alimentação que valorizam, bem como proporciona a expansão de outras capacidades de caráter econômico, cultural e social.

A capacidade de uma pessoa consiste nas combinações alternativas de funcionamentos cuja realização é factível para ela. Portanto, a capacidade é um tipo de liberdade: a liberdade substantiva de realizar combinações alternativas de funcionamentos (a liberdade de ter estilos de vida diversos) (SEN, 2010, p. 105).

Para Ploeg (2008) a produção de subsistência ou auto-abastecimento alimentar pode representar uma forma de sobrevivência e autonomia, mas não necessariamente a única. Para essa afirmação, utiliza como exemplo os camponeses holandeses do século XVII que não produziam mais grãos para subsistência, visto que estes produtos podiam ser importados a preços

\footnotetext{
${ }^{5}$ As liberdades substantivas incluem capacidades elementares, como por exemplo, ter condições de evitar privações como a fome, subnutrição, a morbidez evitável e a morte prematura, bem como as liberdades associadas a saber ler e fazer cálculos aritméticos, ter liberdade política, etc. Nesta perspectiva constitutiva, o desenvolvimento envolve a expansão dessas e de outras liberdades básicas: é o processo de expansão das liberdades humanas, e sua avaliação tem de basear-se nessa consideração.
} 
menores do que seu custo de produção. Desta forma, estes se especializaram na produção de leite e criação de gado. Sendo assim,

Os camponeses adaptam-se constantemente a conjunturas específicas, portanto as especificidades da sobrevivência também se adaptam a elas - sem que isso implique qualquer alteração básica nas próprias condições camponesas (PLOEG, 2008, p. 47).

Nessa perspectiva, Garcia Júnior (1989) identificou elementos relacionados com a decisão das unidades familiares entre produzir para o gasto da casa e produzir lavouras comerciais, como a flutuação dos preços no mercado, a existência de condições técnicas de produção, o consumo alimentar familiar e a disponibilidade de força de trabalho da família. Esses fatores determinam a opção por produzir ou comprar, autoconsumir ou vender determinado alimento.

Segundo Plein (2012), a reprodução da agricultura familiar está relacionada com vários mecanismos, sendo que o processo produtivo pode ser direcionado para dois caminhos. Um destes caminhos é o consumo familiar, podendo desempenhar duas funções, como o consumo direto da família ou como parte integrante do processo produtivo da propriedade. $\mathrm{O}$ outro caminho é o da troca, que pode assumir funções de reciprocidade, redistribuição ou de troca mercantil. Ambos os mecanismos são relevantes para o processo de reprodução social da agricultura familiar, sendo que o presente estudo dedica-se ao caminho percorrido pelo consumo direto da família.

Em seu estudo Ploeg (2008) ressaltou que o processo de aumento dos custos de produção, juntamente com a diminuição dos preços de venda, ou mesmo a sua estagnação é chamado de squeeze da agricultura. Este fato ocasiona a marginalização e adoção de novos padrões de dependência, que impulsionam, por sua vez, os processos de recampesinização. Esta representa "a luta por autonomia e sobrevivência em um contexto de privação e dependência" (PLOEG, 2008).

A tomada de decisão na cultura camponesa não se baseia no valor nominal das coisas, pois considera que a aparência engana. A decisão vem a partir da posição das coisas e de suas relações com o passado, presente e futuro, situando essas coisas com divisões de trabalho e de espaço. Esta desconfiança institucionalizada, na conjuntura atual pode ser compreendida como um anacronismo. Mas, com a dominação controlada pelo Império ${ }^{6}$ e a invasão de imagens

\footnotetext{
${ }^{6} \mathrm{O}$ Império é uma estrutura composta por esquemas reguladores de natureza política e econômica que são impostos à sociedade e à natureza. Diz respeito a uma forma de governança e ordenamento, os elementos centrais neste modelo são o controle e a apropriação. Nessa estrutura e através dela, o Estado e o mercado se tornaram cada vez mais interligados. Um se concretiza no outro e vice e versa. O Império não diz respeito primeiramente a produtos, pessoas, serviços, recursos, lugares, e assim por diante, nem é composto por esses elementos. O Império, é acida de tudo, um conjunto complexo, multifacetado em expansão e cada vez mais monopolista de ligações (isto é, uma rede
} 
virtuais na vida dos indivíduos, tal desconfiança institucionalizada talvez não seja deslocada. Esta pode se tornar uma importante ferramenta de equilíbrio, necessária a evitar desvios irreversíveis conduzidos em nossa sociedade (PLOEG, 2008).

Todas as sociedades apresentam estilos de vida específicos, formas culturais e racionalidades diferentes. Os membros da sociedade se utilizam destes fatores para buscar ordem e significado, sendo assim participam dos processos de afirmação e reestruturação. Neste contexto, nota-se que as estratégias e construções culturais utilizadas por pessoas estão baseados em um estoque de discursos disponíveis, partilhados entre indivíduos contemporâneos e antecessores. Assim, o indivíduo é considerado um ator social, visto que é socialmente construído (LONG; PLOEG, 2011).

Nessa abordagem de ator social, valoriza-se a forma como os agricultores moldam os padrões de desenvolvimento rural. Entender as estratégias utilizadas por estes atores é importante para a compreensão de como os produtores e habitantes rurais resolvem problemas relacionados à sua subsistência e organização dos recursos naturais (LONG; PLOEG, 2011).

\section{Práticas da produção de alimentos para autoconsumo}

Considero a produção de autoconsumo sob sete aspectos: biológico; ambiental; político; social; cultural; econômico e ético (Figura 1). Independente da atividade desenvolvida pela agricultura familiar, a produção de alimentos para autoconsumo está presente, sendo que o sistema produtivo desenvolvido influência nas percepções destes indivíduos, pois estão diretamente relacionadas ao seu modo de viver.

Diante destes aspectos, a proposta desafiadora do presente estudo diz respeito à teoria apresentada por Amartya Sen para o desenvolvimento das sociedades, um "desenvolvimento como liberdade”. A alimentação é um elemento essencial à vida, assim é pertinente trazê-la como elemento de discussão frente à produção de autoconsumo e o desenvolvimento.

Para Sen (2010), o desenvolvimento deve estar relacionado à melhora da vida dos indivíduos e de suas liberdades substantivas, ou seja, das capacidades elementares à vida, como a alimentação. Dessa forma, quando os indivíduos apresentam expansão de suas liberdades, é possível que eles realizem coisas que justamente valorizem, fazendo com que possam cuidar melhor de si mesmas e também influenciar a sociedade, executando a sua função de agente. Esse é o caminho para o verdadeiro desenvolvimento, que prioriza a qualidade de vida, antes dos interesses relacionados à renda.

coerciva) que coloca processos, lugares, pessoas e produtos em contato de uma forma específica (Ploeg, 2008, p. 283) 
Figura 1: A construção do modelo teórico dos aspectos relacionados aos alimentos de autoconsumo.

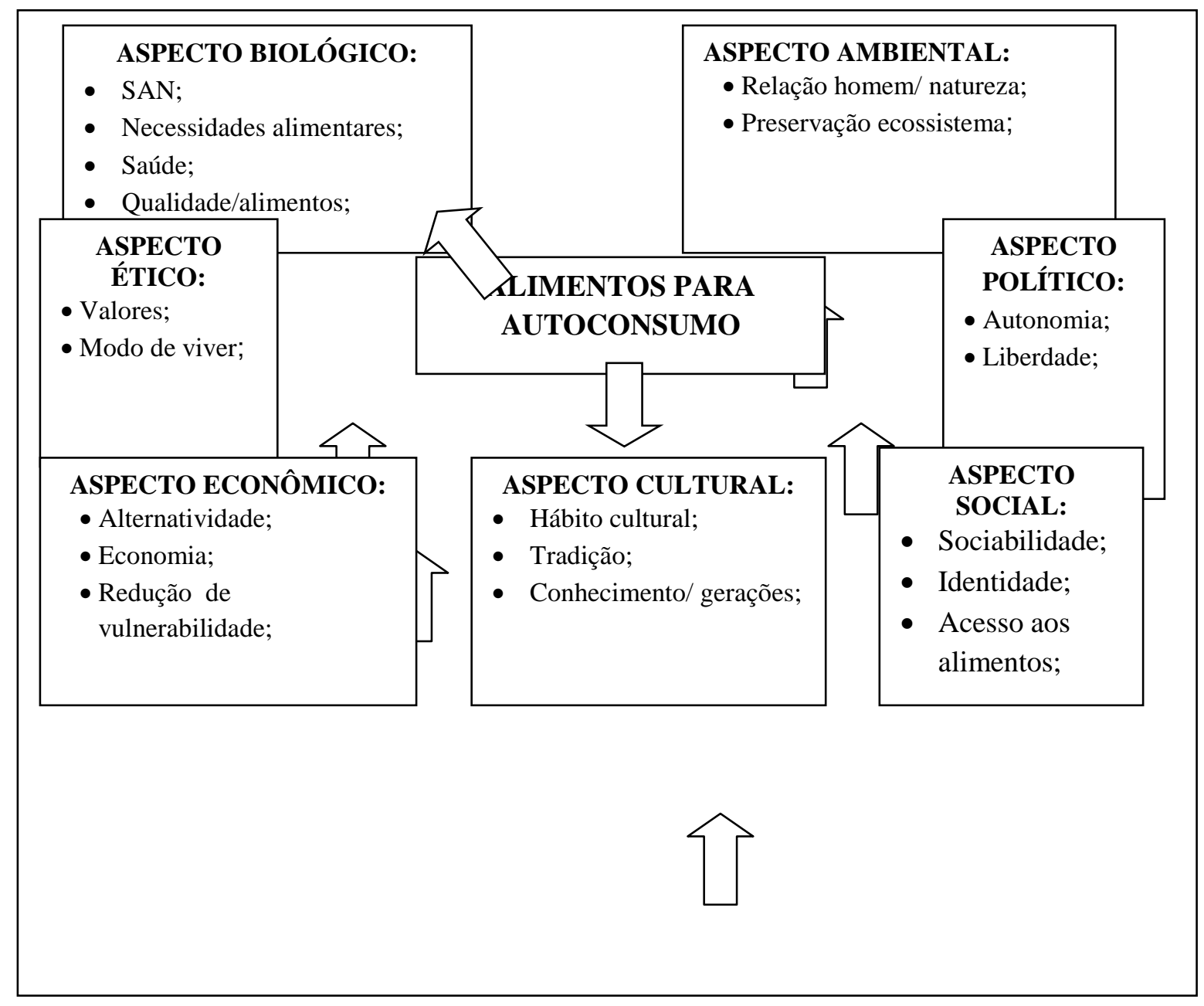

Dessa forma, a produção de alimentos para autoconsumo pode ser interpretada como uma liberdade substantiva dos indivíduos, sendo relevante no contexto da agricultura familiar estudada, visto que representa a capacidade dos indivíduos de reproduzirem a alimentação que valorizam, bem como expandir outras capacidades, sob os aspectos citados.

Diante das percepções e aspectos elencados referente à produção de autoconsumo, da teoria de desenvolvimento dada por Amartya Sen, sugere-se a terminologia da "Liberdade Alimentar", ou seja, a liberdade que os indivíduos que dispõem de alimentos para autoconsumo possuem (Figura 2). 
Figura 2: Liberdade Alimentar

PRODUÇÃO DE ALIMENTOS PARA AUTOCONSUMO FAMILIAR

\section{LIBERDADE ALIMENTAR}

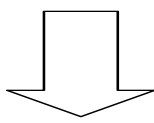

- Capacidade de manter suas necessidades alimentares regularmente, através do acesso a alimentos que considerem saborosos, saudáveis, de qualidade e com procedência conhecida;

- Capacidade de promover a saúde através de alimentos livres de produtos químicos e nutritivos;

- Capacidade de manter a relação com a natureza e preservar o ecossistema através de cultivos livres de agrotóxicos e outros produtos químicos, bem como aumentando as interações no mesmo com policultivos;

- Capacidade de manter a autonomia na propriedade rural, decidindo: o que produzir, como produzir e quando produzir;

- Capacidade de manter a identidade do seu grupo familiar e social, através da sociabilidade e de seus hábitos alimentares;

- $\quad$ Capacidade de manter a sua cultura e tradição alimentar, transmitida de geração para geração do "saber fazer" e do orgulho em "produzir seu próprio alimento".

- Capacidade de escolher entre consumir os produtos ou comercializá-los para manter as necessidades da família. Respeitando suas particularidades, bem como economizando recursos financeiros e reduzindo a sua vulnerabilidade frente às incertezas e oscilações do mercado.

Fonte: Elaboração da autora, 2016

A Liberdade Alimentar está relacionada às capacidades que os indivíduos que produzem alimentos para o autoconsumo desfrutam, ou seja, o que esta produção representa para estes sujeitos. Possuir esta liberdade é tão relevante e faz parte da essência e do modo de viver destes indivíduos, que mesmo enfrentando adversidades eles procuram mantê-la no contexto na agricultura familiar.

Os agricultores que produzem alimentos para autoconsumo e possuem esta "Liberdade Alimentar", se desenvolvem enquanto unidade familiar, contribuindo para o desenvolvimento da sociedade local e territorial, na essência do "Desenvolvimento como Liberdade", propiciando melhora na qualidade de vida dos indivíduos. 


\section{Considerações finais}

Com base no presente estudo, é evidente que a produção de autoconsumo é parte integrante da vida dos agricultores familiares, sendo que sua prática pode ser observada no decorrer dos anos, apesar das intensas transformações, apresentando-se como uma atividade importante para a agricultura familiar na atualidade, representando, entre outros, sua cultura e tradição.

São vários os papéis desempenhados por este tipo de produção no meio rural, tanto em aspectos econômicos, sociais, culturais e ambientais. A produção de autoconsumo é reconhecida como: elemento de promoção da segurança alimentar e nutricional, de qualidade de vida, de redução da pobreza e de economização, de inclusão socioprodutiva, de socialização e identidade de famílias e comunidades, um sistema produtivo mais sustentável, promotora de autonomia na propriedade rural e de reprodução da unidade familiar.

A alimentação é elemento essencial à vida, produzindo os seus próprios alimentos, os agricultores garantem o abastecimento, a procedência e a qualidade dos produtos consumidos pela família. Esse fato é relacionado com uma alimentação diversificada, balanceada, nutritiva e promotora de saúde. Quanto ao sistema produtivo, a produção de autoconsumo, apresenta-se benéfica, pois permite a interação complexa dos elementos da propriedade, melhorando as condições ecológicas da mesma e propiciando o contato entre homem e natureza.

Diante disso, a produção de alimentos para autoconsumo desempenha uma função estratégica de desenvolvimento da unidade familiar e de expansão de liberdades substantivas dos agricultores familiares. Sugerindo a terminologia que representa as percepções e aspectos relacionados à produção de alimentos para autoconsumo, denominada de "Liberdade Alimentar", visto que os agricultores que dispõem destes alimentos apresentam ampliação de certas capacidades, que estão diretamente relacionadas ao desenvolvimento, no sentido de melhorar a qualidade de vida, sob aspectos que estes justamente valorizam e que favorecem o desenvolvimento da unidade familiar.

Nessa perspectiva, considerando que a alimentação representa uma condição essencial de sobrevivência, tais condições deveriam ser prioridades do desenvolvimento de uma nação e como indicadores do êxito de uma sociedade, e não apenas almejar-se um desenvolvimento na perspectiva econômica, o que infelizmente é bastante comum no mundo contemporâneo. Diante do exposto, nota-se a relevância dessa temática, com questões que podem contribuir para ampliação das discussões na literatura. 


\section{Referências}

ABRAMOVAY, Ricardo. Agricultura Familiar e serviço público: novos desafios para a extensão rural. Cadernos de Ciência \& Tecnologia, Brasília, v. 15, n. 1, p. 137-157, jan./abr. 1998.

ANJOS, Flavio Sacco; CALDAS, Nadia Velleda; HIRAI, Wanda Griep. A Dimensão Rural da Insegurança Alimentar: Transformações nas Práticas de Autoconsumo entre Famílias Rurais do Extremo Sul Gaúcho. Revista Segurança Alimentar e Nutricional, Campinas, v. 16, n.1, p. 1$17,2009$.

BRASIL. A produção para autoconsumo no Brasil uma análise a partir do Censo Agropecuário 2006. Relatório de Pesquisa. Brasília, 2013.

BRASIL. Decreto-lei no 11.346, de 15 de setembro de 2006. Disponível em: http://www.planalto.gov.br/ccivil_03/_ato2004-2006/2006/lei/111346.htm. Acessado em: 15 nov. 2016.

CANDIDO, Antonio. Os parceiros do Rio Bonito. Estudo sobre o caipira paulista e a transformação dos seus meios de vida. São Paulo: Livraria Duas Cidades, Editora 34 Ltda, 9a edição, 2001.

FONINI, Regiane; LIMA, José Edmilson Souza. Agrofloresta e alimentação: o alimento como mediador da relação sociedade- ambiente. In: STEEMBOCK, W.; SILVA, L.C.; SILVA, R.O.; RODRIGUES, A.S.; PEREZ-CASSARINO, J.; FONINI, R. (Org.). Agrofloresta, Ecologia e Sociedade. Curitiba: Kairós, 2013. p. 197-231.

GADELHA, Edmar; MALUF, Renato S. Contribuições da produção para autoconsumo no acesso aos alimentos. Democracia Viva, Rio de Janeiro, n. 39, junho, 2008.

GARCIA JÚNIOR, A. O Sul: caminho do roçado. Estratégias de reprodução camponesa e transformação social. São Paulo: Ed. Marco Zero/ Unb, 1989.

GAZOLLA, Marcio; SCHNEIDER, Sergio. A produção da autonomia: os "papéis" do autoconsumo na reprodução social dos agricultores familiares. Revista Estudos Sociedade e Agricultura, Rio de Janeiro: v. 15, p. 89-122, 2007.

GRISA, Catia. Para além da alimentação: papéis e significados da Produção para autoconsumo na agricultura familiar. Revista Extensão Rural, , Ano XIV, Jan - Dez, 2007a.

GRISA, Catia. A produção "pro gasto" um estudo comparativo do autoconsumo no Rio Grande do Sul. Dissertação de mestrado, Universidade Federal do Rio Grande do Sul, Porto Alegre, 2007b.

GRISA, Catia; GAZOLLA, Marcio; SCHNEIDER, Sérgio. A "produção invisível" na Agricultura Familiar: Autoconsumo, segurança alimentar e Políticas Públicas de desenvolvimento rural. Revista Agroalimentaria. Vol. 16, $\mathrm{N}^{\circ} 31$; (65-79) julho - dezembro, 2010 .

LEITE, Sérgio. Orçamentos familiares e estratégias socioeconômicas em assentamentos rurais. Revista Estudos Sociedade e Agricultura, Rio de Janeiro, outubro, 118- 151, 2003.

LONG, Norman; PLOEG, Jan Douwe Van der. Heterogeneidade, ator e estrutura: para reconstituição do conceito de estrutura. In: SCHNEIDER, S. GAZOLLA, M. Os atores desenvolvimento rural: Práticas produtivas e processos sociais emergentes. Editora UFRGS, 2011. 
MACHADO, Luiz Carlos Pinheiro; MACHADO FILHO, Luiz Carlos Pinheiro. A dialética da Agroecologia. Contribuição para um mundo com alimentos sem veneno. São Paulo: Editora Expressão Popular, 2014.

MALUF, Renato S.; MENEZES, Francisco; MARQUES, Susana Bleil. Caderno 'Segurança Alimentar', 2001. Disponível em: <http://www.dhnet.org.br/direitos/sos/alimentacao/tconferencias.html>. Acesso em: 02 jun. 2015.

MENASCHE, Renata. A agricultura familiar à mesa. Saberes e práticas da alimentação no Vale do Taquari. Editora Universidade Federal Rio Grande do Sul. Série Estudos e Pesquisas IEPE, abr., 2007.

MENASCHE, Renata; MARQUES, Flávia Charão; ZANETTI, Cândida. Autoconsumo e segurança alimentar: a agricultura familiar a partir dos saberes e práticas da alimentação. Revista Nutrição, Campinas, 21(Suplemento):145-158, jul./ago., 2008.

PLEIN, Clério. Os mercados da pobreza ou a pobreza dos mercados? As instituições no processo de mercantilização da agricultura familiar na Microrregião de Pitanga, Paraná. Universidade Federal do Rio Grande do Sul, Porto Alegre, 2012.

PLOEG, Jan Douwe Van der. Camponeses e impérios alimentares: lutas pela autonomia e sustentabilidade na era da globalização. Porto Alegre: Editora da UFRGS, 2008.

SARANDÓN, Santiago Javier. La agroecología como enfoque necesario para undesarrollo rural sustentable. In: Agroecología: Referente para latransición de los sistemas agrarios. VI Congresso SEAE Alméria 2004. II Congresso Iberoamericano de Agroecologia. I Encuentro de estudiantes de Agroecología y Agricultura Ecológica. Alméria, Andalúcia, España, 27 de septiembre - 02 de octubredel 2004.

SARANDÓN, Santiago Javier; FLORES, Claudia Cecilia. Agroecología: bases teóricas para el diseño y manejo de agroecosistemas sustentables. ed. - La Plata: Universidad Nacional de La Plata, 2014.

SCHNEIDER, Sérgio. A diversidade da Agricultura Familiar. Porto Alegre: Editora UFRGS, $2^{a}$ edição, 2009.

SEN, Amartya. Desenvolvimento como Liberdade. São Paulo: Companhia das Letras, 2010. 